\title{
Monolayer iron oxide film on platinum promotes low temperature $\mathrm{CO}$ oxidation.
}

\author{
Y.-N. Sun, Z.-H. Qin, M. Lewandowski, E. Carrasco, M. Sterrer, \\ S. Shaikhutdinov*, H.-J. Freund \\ Abteilung Chemische Physik, Fritz-Haber-Institut der Max-Plank-Gesellschaft, \\ Faradayweg 4-6, Berlin 14195
}

\begin{abstract}
CO oxidation on a clean $\mathrm{Pt}(111)$ single crystal and thin iron oxide films grown on $\mathrm{Pt}(111)$ was studied at different $\mathrm{CO}: \mathrm{O}_{2}$ ratios (between 1:5 and 5:1) and partial pressures up to 60 mbar at $400-450 \mathrm{~K}$. Structural characterization of the model catalysts was performed by scanning tunneling microscopy, low energy electron diffraction, Auger electron spectroscopy and temperature programmed desorption. It is found that monolayer $\mathrm{FeO}(111)$ films grown on $\mathrm{Pt}(111)$ are much more active than clean $\mathrm{Pt}(111)$ and nm-thick $\mathrm{Fe}_{3} \mathrm{O}_{4}(111)$ films at all reaction conditions studied. Post-characterization of the catalysts revealed that at $\mathrm{CO}: \mathrm{O}_{2}>1$ the $\mathrm{FeO}(111)$ film dewets the Pt surface with time, ultimately resulting in highly dispersed iron oxide particles on $\operatorname{Pt}(111)$. The film dewetting was monitored in situ by polarisation-modulated infrared reflection absorption spectroscopy. The reaction rate at 450 $\mathrm{K}$ exhibited first order for $\mathrm{O}_{2}$ and non-monotonously depended on $\mathrm{CO}$ pressure. In $\mathrm{O}_{2}$-rich ambient the films were enriched with oxygen while maintaining the long range ordering. Based on the structure-reactivity relationships observed for the $\mathrm{FeO} / \mathrm{Pt}$ films, we propose that the reaction proceeds through the formation of a well-ordered, oxygen-rich $\mathrm{FeO}_{\mathrm{x}}(1<\mathrm{x}$ 2) film that reacts with $\mathrm{CO}$ through the redox mechanism. The reaction induced dewetting in fact deactivates the catalyst. The results may aid in our deeper understanding of reactivity of metal particles encapsulated by thin oxide films as a result of strong metal support interaction.
\end{abstract}

Keywords: platinum, iron oxides, $\mathrm{CO}$ oxidation, strong metal support interaction.

Corresponding author: shamil@fhi-berlin.mpg.de 


\section{Introduction}

The nature of an oxide support plays an important role in catalytic reactions over highly dispersed noble metal catalysts. At a given particle size, the support effects are often rationalized in terms of reactions taking place at the metal/oxide interface or involving spillover of reactive species onto/from an oxide support. These mechanisms are usually considered for transition metal oxides such as titania, ceria, etc. On the other hand, metals supported on the reducible oxides often exhibit socalled strong metal-support interaction (SMSI) [1-6], which in many cases manifests itself by encapsulation (decoration) of the metal particles by a thin layer stemming from the oxide support. Formation of thin titania layers on Pt and Pd particles upon heating in vacuo has recently been investigated by high resolution scanning tunnelling microscopy (STM) [7-9]. It is rather obvious that the decoration will suppress catalytic reactions occurring on metal surfaces and be particularly detrimental for structure sensitive reactions. On the other hand, the reversal of the SMSI state has been observed after $\mathrm{CO}$ hydrogenation reactions on $\mathrm{Pt} / \mathrm{TiO}_{2}[10,11]$. Also, partial recovering of $\mathrm{CO}$ uptake (as a test for the metal encapsulation) upon oxidative treatments of $\mathrm{Pt} / \mathrm{TiO}_{2}(110)$ and $\mathrm{Pt} / \mathrm{CeO}_{2}(111)$ model catalysts has been reported [12,13]. Reversible wetting-dewetting behaviour induced by ambient conditions has recently been demonstrated by in situ STM on vanadia overlayer on $\operatorname{Pd}(111)$ [14]. Therefore, reaction conditions may affect the surface structure and hence the reactivity of catalysts that underwent the encapsulation during catalyst's preparation.

We have recently shown that $\mathrm{Pt}$ supported on iron oxide $\mathrm{Fe}_{3} \mathrm{O}_{4}(111)$ films also exhibits an SMSI effect via encapsulation which is driven by the high adhesion energies between Pt and iron oxide [15,16]. In particular, top facets of the Pt particles heated above $800 \mathrm{~K}$ in vacuum revealed the structure that is very similar to an ultrathin $\mathrm{FeO}(111)$ film grown on a Pt(111) single crystal [17]. This finding suggests that the $\mathrm{FeO}(111) / \mathrm{Pt}(111)$ film is a suitable model system for studying the behaviour of the encapsulated Pt particles.

The adsorption properties of $\mathrm{FeO}(111)$ as well as of $\mathrm{Fe}_{3} \mathrm{O}_{4}(111)$ and $\mathrm{Fe}_{2} \mathrm{O}_{3}(0001)$ films under ultrahigh vacuum conditions were reviewed by Weiss and Ranke [18]. Under the conditions typically used in temperature programmed desorption/reaction (TPD, TPR) studies, the $\mathrm{FeO}$ films were essentially inert towards molecular adsorption (carbon 
monoxide, water, ethylbenzene and styrene). Therefore, the adsorption studies were primarily focused on surfaces of magnetite $\left(\mathrm{Fe}_{3} \mathrm{O}_{4}\right)$ and hematite $\left(\mathrm{Fe}_{2} \mathrm{O}_{3}\right)$ (see also $[19,20]$ ). The inertness of the $\mathrm{FeO}(111)$ film is believed to be related to the fact that the surface exposes a close packed layer of oxygen (the monolayer film stacks as O-Fe-Pt-Pt...). However, it is not obvious per se that the film will maintain the structure upon exposure to realistic reaction conditions. It has been demonstrated that adsorbates, molecules, metal atoms and clusters on thin oxide films supported on metallic substrates may, under certain conditions, induce electron transfer through the film onto the adsorbate [21-27]. Therefore, it is conceivable, that under favorable conditions such electron transfer in turn induces reactivity between molecules. Formation of an appropriate transition state with high probability is almost certainly enhanced under high-pressure conditions. If the chemical potential, set by the gas pressure, is such that one of the reacting components is oxygen, prone to exchange with the oxygen in the film, then restructuring of the film, accompanied by unexpected reactivity, could be observed.

In attempts to shed light on the possible effects of elevated pressures and temperatures on structure and reactivity of thin oxide films, we have recently initiated "highpressure" studies of $\mathrm{FeO} / \mathrm{Pt}$ films with respect to $\mathrm{CO}$ oxidation. To combine both, reactivity studies at atmospheric pressure and a structural control of model catalysts, we used a socalled "high-pressure" cell located inside an ultra-high vacuum (UHV) chamber equipped with different surface-science tools. The sample, having been prepared and characterized under UHV conditions, is sealed in the cell used as a reactor that allows using gas chromatography (GC) analysis of products. In particular, we have found that the $\mathrm{FeO}$ films in 40 mbar of $\mathrm{CO}+20$ mbar $\mathrm{O}_{2}$ at $450 \mathrm{~K}$ show much higher $\mathrm{CO}_{2}$ production than the clean $\operatorname{Pt}(111)$ surface [28]. Tentatively, this unexpected result has been explained on the basis of reaction induced dewetting of the oxide film, resulting in highly dispersed $\mathrm{FeO}_{\mathrm{x}}$ nanoparticles on $\operatorname{Pt}(111)$, thus effectively forming "inverted" catalysts [29].

In this paper, we report an extended study of the structure and reactivity of $\mathrm{FeO}$ films with respect to $\mathrm{CO}$ oxidation at different $\mathrm{CO}: \mathrm{O}_{2}$ ratios, partial pressures and reaction temperatures. The results suggest that the unusual activity of the ultra-thin $\mathrm{FeO}$ films is intimately connected to the formation of an oxygen-rich oxide film reacting with $\mathrm{CO}$ at 
steady state through a red-ox process. However, under CO-rich conditions, a dewetting of the film occurs that causes the catalyst's deactivation.

The paper is organised as follows. First, we show results on $\mathrm{CO}$ oxidation and structural characterization of the $\mathrm{FeO}$ films at stoichiometric $\mathrm{CO}: \mathrm{O}_{2}$ ratios. Then, we provide data on reactivity at different $\mathrm{CO}$ and $\mathrm{O}_{2}$ ratios and partial pressures. Finally, we speculate on a general mechanism for the $\mathrm{CO}$ oxidation reaction on ultrathin $\mathrm{FeO}$ films.

\section{Experimental}

The experiments were performed in three UHV chambers ("TPD-GC", "STM" and "PM-IRAS"), equipped with low energy electron diffraction (LEED), Auger electron spectroscopy (AES) and a quadrupole mass spectrometer (QMS). The TPD-GC chamber houses a high-pressure cell ( $30 \mathrm{ml}$, made of Au-plated $\mathrm{Cu}$ massive block) connected to gas handling lines and a gas chromatograph GC $6890 \mathrm{~N}$ (Agilent). The double-side polished Pt (111) crystal ( $10 \mathrm{~mm}$ in diameter, $1.5 \mathrm{~mm}$ in thickness) was spot-welded to two parallel Ta wires, which were in turn welded to two Ta sticks used for resistive heating and also for cooling by filling a manipulator rod with liquid nitrogen. The temperature was measured by a chromel-alumel thermocouple spot-welded to the edge of the crystal and controlled using a feedback system (Schlichting Phys. Instrum.). The manipulator rod inside the chamber ends with a KF-type flange with a 4 pins electrical feedthrough holding Ta and thermocouple sticks. The reactor is sealed from the UHV chamber using a Viton O-ring placed on top of the reactor matching the flange on the rod.

For high-pressure experiments, $\mathrm{CO}\left(99.995 \%\right.$, Linde) and $\mathrm{O}_{2}(99.999 \%$, AGA $\mathrm{GmbH}$ ) were additionally cleaned using a cold trap kept at $\sim 200 \mathrm{~K}$. The reaction mixtures of $\mathrm{CO}$ and $\mathrm{O}_{2}$ were balanced by $\mathrm{He}$ to 1 bar in a gas handling system. After introduction to the high pressure cell, the gas was circulating with a flow of $3 \mathrm{ml} / \mathrm{min}$ for $20 \mathrm{~min}$ at room temperature to equilibrate the reaction gas flow. During this pretreatment, no $\mathrm{CO}_{2}$ formation was observed. Then the sample was heated up to the reaction temperature with a heating rate of $1 \mathrm{~K} / \mathrm{s}$. The gas composition in the circulating flow was analyzed using a HP-Plot Q column at $35^{\circ} \mathrm{C}$ and a TCD detector. For structural characterisation of the spent catalysts, the crystal was rapidly (within 2-3 minutes) cooled down to room temperature, and the reactor 
was pumped out down to $\sim 10^{-5}$ mbar (which typically takes $\sim 20 \mathrm{~min}$ ) before exposing to UHV.

Basically, a similar design was used in the PM-IRAS chamber, where a single-side polished $\mathrm{Pt}(111)$ crystal was spot-welded by $\mathrm{T}$ wires to Mo rods on the manipulator for resistive heating. The temperature was controlled by a chromel-alumel thermocouple spotwelded to the backside of the crystal. After surface preparation and characterization, the sample was transferred into a stainless steal high-pressure cell $(\sim 11)$ sealed with differentially pumped, spring loaded Teflon O-rings. The cell was equipped with two $\mathrm{CaF}_{2}$ windows for infrared reflection absorption spectroscopy (IRAS) studies using a Bruker IFS 66v spectrometer. Polarisation modulated (PM) IRAS measurements were carried out with a wire-grid polarizer and a photoelastic modulator (Hinds Instruments PEM 90) which modulates the polarisation of the incident infrared light between $\mathrm{p}$ - and spolarized at a frequency of $74 \mathrm{kHz}$. In p-polarisation, both surface and gas-phase species contribute to the absorption signal, while in s-polarisation, only gas-phase species are detected. By calculating the differential absorbance $\Delta R / R=\left(R_{p}-R_{s}\right) /\left(R_{p}+R_{s}\right)$, where indexes $s$ and p are referred to s- and p-polarisations, respectively, a vibrational spectrum of the surface species can be obtained.

In the STM chamber, the Pt(111) crystal was mounted to a Pt sample holder. The temperature was controlled using a chromel-alumel thermocouple spot-welded to the edge of the crystal. The crystal can be heated in the UHV chamber by electron bombardment from the backside using a tungsten filament. For treatments at high pressures the sample was transferred into the Autplated reactor housing a heating stage, consisting of ceramic and sapphire pieces. The sample was heated from the backside using a halogen lamp. The STM images presented here were obtained at tunneling currents of $0.5-0.8 \mathrm{nA}$ and positive sample bias of $0.2-1 \mathrm{~V}$.

The preparation of the ultra-thin $\mathrm{FeO}(111)$ and nm-thick $\mathrm{Fe}_{3} \mathrm{O}_{4}(111)$ films on $\mathrm{Pt}(111)$ is described elsewhere [18]. Briefly, one monolayer (ML) of $\mathrm{Fe}(99.95 \%$, Goodfellow) is deposited onto clean $\mathrm{Pt}(111)$ at $300 \mathrm{~K}$ and subsequently annealed in $10^{-6}$ mbar $\mathrm{O}_{2}$ at $1000 \mathrm{~K}$ for $2 \mathrm{~min}$. Repeated cycles of $5 \mathrm{ML}$ Fe deposition and oxidation results in well ordered $\mathrm{Fe}_{3} \mathrm{O}_{4}(111)$ films. 


\section{Results and discussion}

Before discussing reactivity of model catalysts at elevated pressures, it is instructive here to briefly summarize the results obtained by TPD and TPR for adsorption and coadsorption of $\mathrm{CO}$ and $\mathrm{O}_{2}$ under UHV conditions.

The clean $\mathrm{Pt}(111)$ surface exposed to saturating amounts of $\mathrm{O}_{2}$ (typically, 20 Langmuirs (L), $1 \mathrm{~L}=10^{-6}$ Torr s) and subsequently $\mathrm{CO}$ at $100 \mathrm{~K}$ showed a broad $\mathrm{CO}_{2}$ desorption signal centred at $315 \mathrm{~K}$. In the opposite sequence or exposing the sample to the stoichiometric mixtures of $\mathrm{CO}$ and $\mathrm{O}_{2}(2: 1)$ at $100 \mathrm{~K}$, no $\mathrm{CO}_{2}$ was observed in the TPR spectra. These results are consistent with the well-established $\mathrm{CO}$ poisoning effect on oxygen dissociation.

On the $\mathrm{FeO}(111) / \mathrm{Pt}(111)$ surfaces, the individual TPD spectra of $\mathrm{CO}$ and $\mathrm{O}_{2}$ inversely scale with the $\mathrm{FeO}$ coverage, with no difference in the temperature profiles as compared to the clean $\mathrm{Pt}(111)$, thus indicating no specific adsorption at the rim of $\mathrm{FeO}(111)$ islands formed at sub-monolayer coverage. As expected, the $\mathrm{FeO}(111)$ films fully covering $\mathrm{Pt}(111)$ do not show $\mathrm{CO}_{2}$ formation in TPR spectra, since neither $\mathrm{CO}$ nor $\mathrm{O}_{2}$ adsorbs on the O-terminated $\mathrm{FeO}(111)$ surface at the temperatures used. Note also that long exposures of the $\mathrm{FeO}$ films to $10^{-6} \mathrm{mbar} \mathrm{CO}$ at $500 \mathrm{~K}$ did not reveal any signature of oxide reduction. The results basically confirm the previous conclusions [18] about good thermal stability and chemical inertness of the $\mathrm{FeO}(111)$ films. However, the situation changes dramatically in the mbar-pressure range.

\subsection{Structure and reactivity at stoichiometric $\mathrm{CO}: \mathrm{O}_{2}$ ratios}

Figure 1 shows $\mathrm{CO}_{2}$ evolution upon slow heating of $\mathrm{FeO}(111)$ films in the mixture of 40 mbar $\mathrm{CO}$ and 20 mbar $\mathrm{O}_{2}$ balanced by $\mathrm{He}$ to atmospheric pressure. Carbon dioxide is clearly observed at temperatures above $430 \mathrm{~K}$. The reaction rate apparently increases at increasing temperature as shown in Fig. 2a presenting the kinetics of the $\mathrm{CO}_{2}$ formation at different temperatures. At all temperatures studied, the oxidation rate decreases in time.

For comparison, the clean $\mathrm{Pt}(111)$ surface showed almost no activity under the same conditions (see Fig. 2b), that is consistent with the above TPR results on CO self-poisoning. 
On the other hand, the well-ordered, nm-thick $\mathrm{Fe}_{3} \mathrm{O}_{4}(111)$ films grown on $\mathrm{Pt}(111)$ also exhibited much lower activity than the $\mathrm{FeO}$ films, although higher than of $\mathrm{Pt}(111)$. Therefore, the enhanced activity observed in these experiments must be intimately connected to the ultrathin $\mathrm{FeO}(111)$ film on $\mathrm{Pt}(111)$.

Furthermore, Fig. $2 \mathrm{~b}$ shows that the reactivity of the $\mathrm{FeO}$ films strongly depends on the pressure while keeping the same $\mathrm{CO}: \mathrm{O}_{2}$ ratio. The reaction proceeds much slower when the pressure is reduced from 60 to $15 \mathrm{mbar}$, and then to 6 mbar. The latter fact points either to different reaction orders for $\mathrm{CO}$ and $\mathrm{O}_{2}$ or pressure-dependent surface transformations, or both. Therefore, we first performed a structural characterization of the model catalysts after reaction.

Figure 3 shows LEED patterns of the $\mathrm{FeO} / \mathrm{Pt}$ surface as prepared (a) and after reaction in 60 mbar of a stoichiometric $\mathrm{CO}+\mathrm{O}_{2}$ mixture at 400 (b) and $450 \mathrm{~K}$ (c). The sixspots ring around integer spots is characteristic for the Moire superstructure that arises from the mismatch between $\mathrm{FeO}(111)$ and $\mathrm{Pt}(111)$ lattices [17,18]. No changes are observed by LEED after the reaction at $400 \mathrm{~K}$ indicating that the surface preserves long-range ordering. The conclusion holds true also for the samples treated in 6 mbar at $450 \mathrm{~K}$ (not shown). On the contrary, the sample reacted at $450 \mathrm{~K}$ in 60 mbar of $\mathrm{CO}+\mathrm{O}_{2}$ showed the sharp diffraction spots of $\operatorname{Pt}(111)$ with additional weak spots (Fig. 3c), which are practically identical to those observed on clean $\mathrm{Pt}(111)$ by exposure to $\mathrm{CO}$ and assigned to a $\mathrm{Pt}(111)$ $\mathrm{c}(4 \mathrm{x} 2) \mathrm{CO}$ structure [30]. At intermediate temperatures $(\sim 430 \mathrm{~K})$, a superposition of the $\mathrm{FeO}(111) / \mathrm{Pt}(111)$ and $\mathrm{CO} / \mathrm{Pt}(111)$ structures was observed. Therefore, we conclude that the $\mathrm{FeO}(111)$ films undergo strong reconstruction resulting in a surface exposing a significant fraction of $\mathrm{Pt}(111)$.

The AES study of the spent catalysts revealed only small amounts of carbon beyond the elements, which belong to the original surfaces, as shown in Fig. 4. (In particular, no nickel via Ni carbonyls which may contaminate $\mathrm{CO}$ in high-pressure containers has been detected). Carbon (but no oxygen) has been found on the postreacted $\operatorname{Pt}(111)$ surface most likely due to $\mathrm{CO}$ dissociation on the Pt low coordination sites [31]. Therefore, $\mathbf{i}$ seems plausible that carbon on the $\mathrm{FeO} / \mathrm{Pt}$ surface appears in course of surface reconstructions whereby $\mathrm{CO}$ dissociates on the open $\mathrm{Pt}(111)$ areas. In addition, using the Auger O:Fe signal ratio in the pristine $\mathrm{FeO}$ films as a reference, the iron oxide phase in the post-reacted 
catalysts exhibits $\mathrm{FeO}_{\mathrm{x}}(\mathrm{x} \sim 1.25)$ stoichiometry, on average. Subsequent UHV annealing at temperatures above $800 \mathrm{~K}$ essentially restores both the LEED pattern and the O:Fe ratio of the original film and also removes carbon from the surface (see bottom spectrum in Fig. 4).

In line with LEED data, Auger spectra revealed no significant differences in the surface composition after catalytic tests at lower temperatures and/or lower pressures. The threshold temperature observed for the struc tural changes $(\sim 430 \mathrm{~K})$ basically coincides with the "ignition" temperature in the reaction profile shown in Fig. 1.

To determine the surface morphology of the model catalysts we employed STM. The Pt(111) surface after reaction essentially showed the original topography. Only few small, irregularly shaped particles, presumably of carbon (as judged by AES), and primarily located at the terrace steps were observed [28]. Fig. 5a shows an STM image of a $\mathrm{FeO}(111) / \mathrm{Pt}(111)$ film with atomically flat, wide terraces exhibiting Moire superstructure with a periodicity $\sim 2.6 \mathrm{~nm}$. After 10 minutes exposure to the $40 \mathrm{mbar} \mathrm{CO}+20 \mathrm{mbar} \mathrm{O}_{2}$ mixture at $450 \mathrm{~K}$, small particles emerge on the surface (see Fig. 5b), whereas the rest of the surface shows FeO-like superstructure. The large-scale STM images show that the reconstruction proceeds homogeneously on the whole film. After 120 min the surface is covered by nanoparticles as shown in Figs. 5c and 6a. The particles exhibit a narrow size distribution of $8 \pm 1 \mathrm{~nm}$ in diameter and $1.8 \pm 0.1 \mathrm{~nm}$ in height, and are assigned to iron oxide particles formed on $\mathrm{Pt}(111)$ upon dewetting of a $\mathrm{FeO}$ film. Stepwise annealing in UHV results in the oxide re-wetting (see Fig. 6), in full agreement with the LEED and AES results.

In order to obtain in situ information on surface restructuring we employed PMIRAS that allowed monitoring surface species simultaneously with the gas-phase composition. Figure $7 \mathrm{a}$ shows a series of spectra in the $\mathrm{CO}$ stretching region obtained from the $\mathrm{FeO}(111) / \mathrm{Pt}(111)$ surface at $450 \mathrm{~K}$ in a reaction mixture of $40 \mathrm{mbar} \mathrm{CO}$ and 20 mbar $\mathrm{O}_{2}$ (balanced by He). The spectrum for a $\operatorname{Pt}(111)$ crystal under the same conditions for $120 \mathrm{~min}$ is also shown for comparison.

The absorption band at $\sim 2095 \mathrm{~cm}^{-1}$ that grows with time is characteristic for atop (or terminal) $\mathrm{CO}$ species on $\mathrm{Pt}(111)$. In addition, a broad band centred at $\sim 1865 \mathrm{~cm}^{-1}$ develops, which is typical for $\mathrm{CO}$ occupying bridge position, i.e., consistent with the formation of $\mathrm{c}(4 \mathrm{x} 2)-\mathrm{CO}$ overlayer on $\mathrm{Pt}(111)$ observed by LEED. The integral intensity of 
two bands apparently saturates after $\sim 60$ min of the reaction as shown in Fig. $7 \mathrm{~b}$, finally exposing approximately $70 \%$ of $\mathrm{Pt}(111)$. Therefore, the PM IRAS results unambiguously show that an $\mathrm{FeO}$ film dewets a Pt substrate under the reaction conditions, thus exposing a $\operatorname{Pt}(111)$ substrate. Interestingly, the major peak at $2095 \mathrm{~cm}^{-1}$ revealed a low frequency shoulder (centered at $\sim 2075 \mathrm{~cm}^{-1}$ ), which remained after sample cooling and pumping the reactor out. Therefore, this feature can hardly be assigned to $\mathrm{CO}$ adsorbed on Lewis $\left(\mathrm{Fe}^{2+}\right)$ sites on iron oxide particles as $\mathrm{CO}$ desorbs from iron oxide surfaces below room temperature [32]. On the other hand, this feature is missing in the spectra for $\operatorname{Pt}(111)$ under the same conditions. Therefore, its presence on the dewetted surface could be linked to the oxide/metal interface formed upon dewetting.

Figure $7 \mathrm{~b}$ shows the time evolution of integral amounts of $\mathrm{CO}$ adsorbed on the surface and of $\mathrm{CO}_{2}$ produced in the reaction as obtained by the respective surface and gasphase IR signals. The kinetics of the $\mathrm{CO}_{2}$ production resembles that of the $\mathrm{GC}$ experiments presented in Fig. 2, both showing that the $\mathrm{CO}$ oxidation rate (the slope of the $\mathrm{CO}_{2}$ production curve) decreases with time. It is clearly seen that the highest rate is observed at the beginning of the reaction where the surface is essentially non-dewetted (see more in the next section). With increasing degree of dewetting the reaction rate slows down and stays practically constant as the maximum dewetting is obtained. At this stage, the $\mathrm{CO}_{2}$ formation rate is almost equal to that observed for a $\mathrm{Pt}(111)$ single crystal (not shown here). Note that, under the conditions studied, the $\mathrm{CO}$ conversion is very low $(<1 \%)$; therefore we can neglect the changes in the gas composition during the reaction.

Further information on the structure of the post-reacted $\mathrm{FeO} / \mathrm{Pt}$ surfaces was obtained by TPD. Only $\mathrm{CO}$ and $\mathrm{CO}_{2}$ were found as desorbing species upon heating of the spent catalysts in UHV. After reaction at low temperatures, a broad and rather featureless $\mathrm{CO}$ desorption signal at $350-450 \mathrm{~K}$ is observed (Fig. 8). (Note, that the pristine FeO films do not adsorb $\mathrm{CO}$ even at $90 \mathrm{~K}$ ). With increasing the reaction temperature, a peak at $\sim 390 \mathrm{~K}$ develops which superimposes with the signal at 320 - $500 \mathrm{~K}$ gaining intensity. Except the prominent feature at 380-390 K, the TPD spectra are similar to that observed after CO adsorption on clean $\operatorname{Pt}(111)$ shown in the same graph for comparison. The desorption traces of $\mathrm{CO}$ and $\mathrm{CO}_{2}$ at $\mathrm{T}>500 \mathrm{~K}$, which are missing in the spectra for $\mathrm{Pt}(111)$, may be attributed to the reaction of carbonaceous species with surface oxygen (e.g., see [39]). This oxygen is 
apparently coming from the iron oxide particles since the carbon peak in AES spectra disappears upon heating to $800 \mathrm{~K}$ with a simultaneous restoration of the Auger O:Fe ratio (see Fig. 6). Annealing at $\mathrm{T}>800 \mathrm{~K}$ leads again to the chemical inertness towards $\mathrm{CO}$, as it essentially recovers the structure of the $\mathrm{FeO}(111)$ films as judged by LEED, AES and STM.

Regarding the desorption peak at $\sim 380 \mathrm{~K}$, it cannot be assigned to $\mathrm{CO}$ adsorbed on iron oxide particles [32]. Note that this peak was only observed on strongly dewetted surfaces (e.g., after reaction in $60 \mathrm{mbar}$ at $450 \mathrm{~K}$ ) and never under O-rich reaction conditions (see below). Also, the peak does not show up in the next CO TPD runs, i.e., after the first heating to $600 \mathrm{~K}$. On the other hand, narrow $\mathrm{CO}$ desorption signals are typical for decomposition of metal carbonyls (e.g., [33, 34]). Indeed, $\mathrm{Pt}_{\mathrm{x}}(\mathrm{CO})_{\mathrm{y}}$ species prepared on $\mathrm{Pt}(111)$ by physical vapour deposition of $\mathrm{Pt}$ in $10^{-6} \mathrm{mbar}$ of $\mathrm{CO}$ at $100 \mathrm{~K}$ revealed a similar TPD peak at $\sim 380 \mathrm{~K}$ superimposed with the signal from $\mathrm{CO} / \mathrm{Pt}(111)$ as shown in Fig. 8. Therefore, we may assign this desorption feature, observed on the spent catalysts, to $\mathrm{Pt}$ carbonyl-like species formed upon film dewetting the Pt surface. Its absence on the postreacted $\mathrm{Pt}(111)$ sample indicates that these species are probably stabilized by the iron oxide particles formed. This conclusion is also consistent with the observation of a low frequency shoulder on the $2095 \mathrm{~cm}^{-1}$ band on $\mathrm{FeO} / \mathrm{Pt}$ and not on $\mathrm{Pt}(111)$ surface in the PM-IRAS experiments (see Fig. 7a).

One could, in principle, suggest the formation of iron carbonyls upon reduction of the $\mathrm{FeO}$ film at high $\mathrm{CO}$ pressures. However, previous studies showed that $\mathrm{Fe}_{\mathrm{x}}(\mathrm{CO})_{\mathrm{y}}$ species $\left(\mathrm{x}=1-3 ; \mathrm{y}=5\right.$ 12) exhibit the $2064 \mathrm{~cm}^{-1}$ band as the highest for the terminal CO stretch (e.g., [34-36]), which is well below than the shoulder at $2075 \mathrm{~cm}^{-1}$ observed in Fig. 7a. Formation of highly reduced or metallic Fe particles adsorbing $\mathrm{CO}$ can be excluded either. Indeed, $\mathrm{CO}$ on oxide supported Fe nanoparticles showed the band at $\sim 2030 \mathrm{~cm}^{-1}$ [37]. In addition, if formed upon reduction of the $\mathrm{FeO}$ film, the $\mathrm{Fe}$ overlayer on $\mathrm{Pt}(111)$ would manifest itself by the IRAS signal either at $\sim 1950 \mathrm{~cm}^{-1}$ (at $343 \mathrm{~K}$ ) or at $2060 \mathrm{~cm}^{-1}$ (at $473 \mathrm{~K}$ ), the latter being due to $\mathrm{Fe}$ migration into the sub-surface region as reported in [38]. All scenarios are inconsistent with the spectra shown in Fig. 7a.

In addition to PM-IRAS, we used the TPD results for estimating the degree of dewetting (determined here as a percentage of the $\operatorname{Pt}(111)$ substrate that opens during a reaction) by integrating the CO TPD signal between 300 and $500 \mathrm{~K}$. Using the TPD 
spectrum for $\mathrm{CO} / \mathrm{Pt}(111)$ as a reference, we found that approximately $70 \%$ of the surface expose the $\operatorname{Pt}(111)$ after reaction at $450 \mathrm{~K}$ for $2 \mathrm{~h}$. This value nicely agrees with that obtained by PM-IRAS. It has turned out that the integral $\mathrm{CO}$ intensity vs reaction temperature relationship fits well the Arrhenius plot as shown in the inset in Fig. 8, from which the activation energy $\sim 70 \mathrm{~kJ} / \mathrm{mol}$ is calculated. The analysis with a proper subtraction of the feature at $\sim 380 \mathrm{~K}$ in the TPD spectra results in a bit smaller value, $\sim 65 \mathrm{~kJ} / \mathrm{mol}$. Therefore, $65-70 \mathrm{~kJ} / \mathrm{mol}$ may be considered in the first approximation as the activation energy for the $\mathrm{FeO}$ film dewetting; however, this value will depend on pressure and $\mathrm{CO}: \mathrm{O}_{2}$ ratio.

Note, that according to the TPD studies, no dewetting is observed after individual exposures of $\mathrm{FeO}$ films to $40 \mathrm{mbar} \mathrm{CO}$ or $20 \mathrm{mbar}_{2}$ at $450 \mathrm{~K}$. In both cases, the LEED patterns revealed a Moire superstructure. It is therefore clear that dewetting is a reactioninduced process.

\section{2. $\mathrm{O}_{2}$-rich vs $\mathrm{CO}$-rich reaction conditions}

It is well documented in the literature that the $\mathrm{CO}$ oxidation rate on $\mathrm{Pt}$ catalysts strongly depends on $\mathrm{CO}: \mathrm{O}_{2}$ partial pressures ([39,41] and references therein). Therefore, one may raise the question about whether the promoting effect of the ultrathin $\mathrm{FeO}$ films exists in a wide range of $\mathrm{CO}$ and $\mathrm{O}_{2}$ partial pressures. To study possible effects of the gas composition on reactivity of the $\mathrm{FeO}$ films, we carried out two sets of experiments in various $\mathrm{CO}+\mathrm{O}_{2}$ mixtures. In the first set, we varied the $\mathrm{O}_{2}$ pressure while keeping the $\mathrm{CO}$ partial pressure at 10 mbar. In the second one, we kept the $\mathrm{O}_{2}$ partial pressure constant at 20 mbar and varied the $\mathrm{CO}$ pressure. In two sets the $\mathrm{CO}: \mathrm{O}_{2}$ ratio was varied between 1:5 and 5:1 which basically covers both $\mathrm{O}_{2}$ - and $\mathrm{CO}$-rich regimes. The mixtures were always balanced by He to 1 bar, and the reaction was monitored at $450 \mathrm{~K}$. After reactivity measurements, the surfaces were characterized by LEED, TPD and AES.

Figure 9 shows the kinetics of $\mathrm{CO}_{2}$ production at different $\mathrm{CO}$ and $\mathrm{Q}$ partial pressures. Under CO-lean conditions the reaction rate is almost constant in time and increases while approaching $100 \%$ conversion of CO. In contrast, the reaction slows down in the $\mathrm{CO}$-rich conditions. Note, that the reaction rate was not much affected by $\mathrm{CO}_{2}$ 
accumulation in the circulating gas mixture. Pumping out the reactor and refilling the line with a fresh $\mathrm{CO}+\mathrm{O}_{2}$ mixture had basically no effect on the subsequent activity, thus indicating that $\mathrm{CO}_{2}$ is not involved in the deactivation process. For further analysis we present the rates measured in the first minutes of reaction (i.e., extrapolated to zero conversion on yet non-deactivated catalysts), if not specified.

Figure 10a depicts the reaction rate as a function of oxygen pressure. The reaction kinetics exhibits first order $(n=1.1 \pm 0.1)$ for $\mathrm{O}_{2}$. This may straightforwardly explain the results of Fig. $2 \mathrm{~b}$ showing much lower $\mathrm{CO}_{2}$ production upon decreasing the total $\mathrm{CO}+\mathrm{O}_{2}$ (2:1) pressure from 60 down to 6 mbar. The reaction order measured on $\operatorname{Pt}(111)$ under the same conditions is close to unity $(n=0.85 \pm 0.1)$ and is consistent with the previous studies [42]. The figure shows that the $\mathrm{FeO} / \mathrm{Pt}$ catalysts exhibit much higher activity than $\mathrm{Pt}(111)$ in the whole pressure range studied.

The temperature dependence of the reaction rate measured at $410-450 \mathrm{~K}$ in the mixture of 10 mbar $\mathrm{CO}$ and 20 mbar $\mathrm{O}_{2}$ leads to an Arrhenius plot with an apparent activation energy of $113 \pm 5 \mathrm{~kJ} / \mathrm{mol}$. Due to the very low conversion, it was impossible to precisely measure the activation energy on $\mathrm{Pt}(111)$ for comparison. Nevertheless, this value is significantly lower than $\sim 135 \mathrm{~kJ} / \mathrm{mol}$, reported for supported Pt catalysts and Pt single crystal surfaces for conditions where CO is the primary surface species $[40,42]$, which is in turn very close to the desorption energy of $\mathrm{CO}$ from $\mathrm{Pt}[30,31]$.

The reaction is accompanied by remarkable structural changes detected by AES. The film becomes enriched with oxygen upon increasing $\mathrm{O}_{2}$ pressure, and approaches the O:Fe ratio close to 2, on average (see Fig. 10b). Interestingly, the corresponding LEED patterns (not shown here) are in fact similar to those of the pristine $\mathrm{FeO}(111) / \mathrm{Pt}(111)$ surface. Another intriguing finding is that the degree of dewetting (see Fig. 10c) basically shows no direct relationship to activity (Fig. 10a). In fact, in the $\mathrm{O}_{2}$-rich atmosphere the inverse relation is observed such that the activity is the highest for the least dewetted surface.

In the next step, we review experimental results of the second set of experiments. Figure 11 shows the reaction rate (a), average stoichiometry of the iron oxide film (b), and degree of dewetting (c) as a function of CO partial pressure. Note, that under the same conditions the $\operatorname{Pt}(111)$ surface showed zero-order kinetics for $\mathrm{CO}$ at $450 \mathrm{~K}$, i.e., in full agreement with the previous studies [42]. Figure 11a reveals again, that the $\mathrm{FeO}$ films are 
much more active than $\mathrm{Pt}(111)$ in the whole $\mathrm{CO}$ pressure range studied. The initial reaction rate vs $\mathrm{CO}$ pressure relationship is not monotonous and has a maximum at $\mathrm{CO}: \mathrm{O}_{2} \sim 1$. Apparently, at high $\mathrm{CO}$ pressures the reaction exhibits negative reaction order, and the catalytic activity decreases with time (see Fig. 9b and also Fig. 2). The data measured after 2 $\mathrm{h}$ on stream are also shown in Fig. 10a, for comparison.

The dewetting process remarkably accelerates at $\mathrm{CO}$ pressures above 10 mbar (see Fig. 11c) leading to a degree of dewetting of $\sim 70 \%$ as the upper limit. However, LEED and TPD inspections of selected samples after 20 - $30 \mathrm{~min}$ on stream, i.e., before the deactivation sets in, showed negligible dewetting. Note also, that in the first set of experiments the highest activity is observed for the non-dewetted surfaces. Finally, the PMIRAS results (see Fig. 7b) showed in situ that the reaction rate is the highest in the first minutes of reaction. Therefore, we conclude that dewetting in fact causes the catalyst's deactiviation rather than forming the most active phase as originally proposed [28].

Finally, under O-rich conditions, the iron oxide becomes enriched with oxygen. Interestingly, O-enrichment apparently mirrors the degree of dewetting (see Figs. 11(b,c)).

\subsection{General discussion and proposed mechanism}

The key observations presented in the previous sections can be summarized as follows.

(i) $\mathrm{FeO}(111)$ monolayer films grown on $\mathrm{Pt}(111)$ show much higher $\mathrm{CO}$ oxidation activity than $\mathrm{Pt}(111)$ at $400-450 \mathrm{~K}$ in a wide range of $\mathrm{CO}: \mathrm{O}_{2}$ ratios (between 1:5 and 5:1). The effect is observed only in the mbar pressure range.

(ii) The reaction is accompanied by strong structural transformations. In $\mathrm{O}_{2}$ rich ambient, the films become enriched with oxygen while maintaining the long range ordering. Under CO-rich conditions, the films undergo dewetting that causes the catalyst's deactivation. Dewetting is a reaction induced process and cannot be observed in pure $\mathrm{O}_{2}$ or $\mathrm{CO}$ ambient.

(iii) The reaction rate at $450 \mathrm{~K}$ exhibits first order for $\mathrm{O}_{2}$ and nonmonotonously depends on $\mathrm{CO}$ pressure. 
In addition, it appears that the reaction does not exhibit an induction period, or the latter is shorter than our acquisition time ( $5 \mathrm{~min})$ (see Fig. 2 and Fig. 9). Under O-rich conditions, the film is enriched with oxygen and does not undergo dewetting that in turn slows down the reaction rate in the CO-rich atmosphere (see Figs. 911). These findings suggest that the surface of the O-rich film formed at elevated $\mathrm{O}_{2}$ partial pressures is in fact the most active. The surface transformations resulting in this surface seem to be relatively fast since the reaction rate in the O-rich atmosphere is practically constant from the onset.

The lack of structural information of the reconstructed $\mathrm{FeO}_{\mathrm{x}}$ film surface renders the reaction mechanism uncertain. Oxidation reactions on oxides are usually considered within a Mars-van Krevelen scheme [43] which invokes a surface redox process where the reactant is oxidized by lattice oxygen and the reduced catalyst is subsequently reoxidized by molecular oxygen. However, the recent analysis by Vannice [44] revealed a number of inconsistencies in the assumptions incorporated into the derivation of the rate expression, even though still the experimental data may be fitted.

Oxidation of $\mathrm{CO}$ on iron oxides $\left(\mathrm{Fe}_{2} \mathrm{O}_{3}\right)$ has been previously studied both experimentally and theoretically [45-48]. The reaction is typically carried out at temperatures above $500 \mathrm{~K}$ in excess of oxygen, although the reaction may occur even in the absence of external oxygen over iron oxide nanoparticles [45]. It was found that the reaction proceeds through dissociative adsorption of $\mathrm{O}_{2}$, which is considered to be a non-activated process, and removal of oxygen by a gas-phase $\mathrm{CO}$ via an Eley-Rideal type mechanism. The reaction showed zero-order kinetics for $\mathrm{Q}$ and first order for $\mathrm{CO}$ at $520-570 \mathrm{~K}$ [44,45]. Microkinetic modeling revealed that the reaction between $\mathrm{CO}$ and surface $\mathrm{O}$ species is the rate-determining step [46]. The Eley-Rideal mechanism was corroborated theoretically for the (100) surface of $\mathrm{Fe}_{2} \mathrm{O}_{3}$, whereas on the oxygen terminated (0001) surface the preference towards the Langmuir-Hinshelwood mechanism (i.e., $\mathrm{CO}$ adsorption before reaction with $\mathrm{O}$ ) was observed [47].

Certainly, in these studies the bulk structure of iron oxide was assumed to remain unchanged during reaction, whereas the monolayer $\mathrm{FeO}$ films undergo strong transformations, which should be taken into account in the reaction kinetics. Qur results showed first order kinetics for $\mathrm{O}_{2}$, i.e., in variance to the above-mentioned iron oxides 
catalysts showing zero order. Therefore, it may well be that the oxygen pressure dependence reflects the kinetics of structural transformations resulting in the O-rich phase rather than the reaction itself. It seems plausible that the whole reaction starts with the formation of the Orich surface domains, which react with $\mathrm{CO}$ producing $\mathrm{CO}_{2}$. The lattice oxygen is then replenished from the gas phase. In excess of $\mathrm{CO}$ the formation of the O-rich film competes with the film reduction accompanied by dewetting.

The atomic structure of the Orich surface is still unclear. However, we may speculate on possible structures. The $\mathrm{FeO}$ films, either treated by pure $\mathrm{O}_{2}$ or reacted at low $\mathrm{CO}: \mathrm{O}_{2}$ ratios at $450 \mathrm{~K}$, showed LEED patterns, which are very similar to those of the pristine $\mathrm{FeO}(111) / \mathrm{Pt}(111)$ surface. On the other hand, these films accommodate much more oxygen (without loosing $\mathrm{Fe}$ ), thus approaching the average $\mathrm{Fe}: \mathrm{O}$ ratio clos e to 1:2 as judged by AES (see Fig. 10b). Therefore, we have tentatively proposed that a $\mathrm{FeO}$ film, originally composed of $\mathrm{Fe}$ and $\mathrm{O}$ close-packed layers stacked as $\mathrm{OFe} / \mathrm{Pt}$, reconstructs at high $\mathrm{O}_{2}$ pressures into a O-Fe-O/Pt -like ("sandwich") structure. Indeed, STM images of the $\mathrm{FeO}(111)$ films treated with 20 mbar of $\mathrm{O}_{2}$ at $450 \mathrm{~K}$ showed long-range modulation which is very similar to that of pristine $\mathrm{FeO}$ (Fig. 12).

Certainly, whenever reactions at elevated pressures are carried out, very careful attention needs to be considered towards impurities in the feedstock, particularly to those having high reaction probability. There are evidences in the literature showing that oxide surfaces may be very sensitive to the traces of water in an ambient, even in the vacuum background $[49,50]$.

In order to see whether water and hydrogen as impurities in the reaction ambient affect the reactivity data presented in Figs. 9-11, we have performed experiments in the TPD-GC setup using the mixture of 10 mbar $\mathrm{CO}+50$ mbar $\mathrm{O}_{2}$ with additional 0.5 mbar of water. The results showed no effect of water on reactivity under these conditions. Meanwhile, adding 0.5 mbar of $\mathrm{H}_{2}$ to a $\mathrm{CO}+\mathrm{O}_{2}$ mixture dramatically increased the reaction rate, by factor of 2 . However, in the latter case the $\mathrm{FeO}(111)$ film reconstructs in a different manner, and the reaction most likely proceeds through the different mechanism (to be discussed in forthcoming paper).

In addition, we have examined thermal stability of the $\mathrm{O}$-rich $\mathrm{FeO}_{\mathrm{x}}$ films formed by exposure to $20 \mathrm{mbar} \mathrm{O}_{2}$ at $450 \mathrm{~K}$ for $20 \mathrm{~min}$. The TPD spectra on heating to $1200 \mathrm{~K}$ (not 
shown) showed $\sim 90 \%$ increase of oxygen content as compared to the pristine film, i.e. consistent with the AES results presented in Figs. 10-11, but did not reveal water desorption. Only tiny amounts of water, as calibrated by water TPD on pristine $\mathrm{FeO}$ [51], was found desorbing in a broad signal at $400-700 \mathrm{~K}$ upon adding 0.15 mbar of $\mathrm{H}_{2}$ into 20 mbar of $\mathrm{O}_{2}$. Therefore, the TPD results suggest no hydroxyls to be present on the O-rich film surface under reaction conditions.

On the other hand, IRAS study of the FeO films exposed to $20 \mathrm{mbar}$ of $\mathrm{O}_{2}$ at $300 \mathrm{~K}$ in the PM-IRAS setup, having much higher reactor volume ( 11 vs $30 \mathrm{ml}$ in GC setup), revealed an absorption band at $3642 \mathrm{~cm}^{-1}$ that shifts to $3625 \mathrm{~cm}^{-1}$ upon heating to $450 \mathrm{~K}$. This band corresponds to the stretching mode of "isolated" (not H-bonded) OH species. The band stayed basically unchanged after pumping oxygen out and disappeared upon heating in vacuum above $500 \mathrm{~K}$, accompanied by water desorption clearly seen in TPD spectra. The unexpected observation of surface hydroxyls on the $\mathrm{O}_{2}$-treated films can be explained either by impurities in the feedstock or those are formed by reactions on the stainless steal reactor walls and gas handling lines. These species were not observed in $10 \mathrm{mbar}$ of pure $\mathrm{CO}$ and 1 mbar of pure $\mathrm{H}_{2}$, and only with minor abundance in 1 mbar of water. Note, that the latter amounts are far above those expected as impurity in the reactor filled with 20 mbar of $\mathrm{O}_{2}$. These findings therefore suggest that $\mathrm{OH}$ species are in fact formed as a result of the reaction of $\mathrm{H}_{2}$ or water with the film first formed upon interaction of $\mathrm{FeO}$ with $\mathrm{O}_{2}$. It appears that O-rich film is extremely reactive towards traces of hydrogen (or water) in the background, ultimately forming $\mathrm{OH}$ species. The resulted film is probably reminiscent of iron oxyhydroxides. Whether this may be connected to results on reduction of $\mathrm{FeO}$ films with atomic hydrogen $[52,53]$ is not clear yet.

\section{Summary}

In this paper, we have shown that a thin $\mathrm{FeO}$ film exhibits enhanced activity towards $\mathrm{CO}$ oxidation as compared to clean $\mathrm{Pt}(111)$ and the nm-thick $\mathrm{Fe}_{3} \mathrm{O}_{4}(111)$ films in a wide range of $\mathrm{CO}: \mathrm{O}_{2}$ ratios at $450 \mathrm{~K}$. Post-characterization of the model catalysts using STM, LEED, AES and TPD shows, that the reaction most likely proceeds through the formation of an oxygen-rich $\mathrm{FeO}_{\mathrm{x}}(1<\mathrm{x}<2)$ film that reacts with $\mathrm{CO}$ via the redox mechanism. The $\mathrm{O}$ 
rich film tends to dewet at $\mathrm{CO}: \mathrm{O}_{2}>1$, ultimately resulting in highly dispersed iron oxide particles on $\mathrm{Pt}(111)$. The film dewetting was monitored in situ by PM-IRAS. The wetting/dewetting process is reversible depending on the ambient conditions.

Such strong restructuring of the $\mathrm{O}$-terminated $\mathrm{FeO}$ surface, in particular the formation of the well-ordered, oxygen-rich film at elevated $\mathrm{O}_{2}$ pressures, implies an enhanced reactivity of ultrathin films towards gas phase molecules, otherwise inert at low pressures and/or on thick oxide films. This situation apparently links the reactivity of a thin oxide film to the presence of a metal substrate underneath and electron transfer processes recently highlighted in the literature [21-27]. In turn, the results may aid in our deeper understanding of the reactivity of metal particles encapsulated by oxide films as a result of strong metal support interaction, e.g., $\mathrm{Pt} / \mathrm{TiO}_{2}, \mathrm{Pt} / \mathrm{CeO}_{2}, \mathrm{Pt} / \mathrm{Fe}_{3} \mathrm{O}_{4}$, etc. Vibrational and electron spectroscopy studies with the goal to identify the nature of the oxygen rich phase are underway.

\section{Acknowledgments.}

We acknowledge support from the Deutsche Forschungsgemeinschaft (DFG) through SFB546 ("Structure and reactivity of transition metal oxides") and the Cluster of Excellence "Unifying concepts in catalysis" (UNICAT), coordinated by TU Berlin, and the Fonds der Chemischen Industrie. Y.-N.S thanks International Max Planck Research School "Complex Surfaces in Materials Science". E.C. thanks the Spanish Ministry of Science and Innovation for a fellowship. 


\section{References}

[1] S.J. Tauster, S.C. Fung and R.L. Garten, J. Am. Chem. Soc. 100 (1978) 170.

[2] E. Ko, R. Garten, J. Catal. 68 (1981) 223.

[3] S.J. Tauster, Acc. Chem. Ress. 20 (1987) 389.

[4] F. Solymosi, J. Catal., 94 (1985), 581.

[5] G.L. Haller, D.E. Resasco, Adv. Catal. 36 (1989) 173.

[6] F. Pesty, H.P. Steinrück, T.E. Madey, Surf. Sci. 339 (1995) 83.

[7] O. Dulub, W. Hebenstreit, U. Diebold, Phys. Rev. Lett. 84 (2000) 3646.

[8] M. Bowker, P. Stone, P. Morrall, R. Smith, R. Bennett, N. Perkins, R. Kvon, C. Pang, E. Fourre, M. Hall, J. Catal. 234 ( 2005) 172.

[9] F. Silly, M.R. Castell, J. Phys. Chem. B 109 (2005) 12316.

[10] K.J. Blankenburg, A.K. Datye, J. Catal. 128 (1991) 186.

[11] A.K. Datye, D.S. Kalakkad, M.H. Yao, D.J. Smith, J. Catal. 155 (1995) 148.

[12] S. Bernal, J.J. Calvino, M.A. Cauqui, J.M. Gatica,J.A. Perez Omil, J.M. Pintado, Catal. Today 50 (1999) 175.

[13] D.R. Mullins, K.Z.Zhang, Surf. Sci., 513(2002), 163.

[14] S. Surnev, J. Schoiswohl, G. Kresse, M.G. Ramsey, F.P. Netzer, Phys. Rev. Lett. 89 (2002) 246101.

[15] Z.H. Qin, M. Lewandowski, Y.N. Sun, S. Shaikhutdinov, H.-J. Freund, J. Phys. Chem. C. 112 (2008) 10209.

[16] Z.H. Qin, M. Lewandowski, Y.N. Sun, S. Shaikhutdinov, H.-J. Freund, J. Phys.: Condens. Matter, 21 (2009) 134019.

[17] H.C. Galloway, P. Sautet, M. Salmeron, Phys. Rev. B 54(1996), R11145.

[18] W. Weiss, W. Ranke, Progr. Surf. Sci., 70 (2002) 1.

[19] R. S. Cutting, C.A. Muryn, G. Thornton, D.J. Vaughan, Geochim. Cosmochim. Acta, 79 (2006) 3593.

[20] K. Abib, D.R. Mullins, G. Totir, N. Camillione, J.P. Fitts, K.T. Rim, G.W. Flynn, R.M. Osgood, Surf. Sci. 537 (2003) 191.

[21] G. Pacchioni, L. Giordano, M. Baistrocchi, Phys. Rev. Lett. 94 (2005), 226104.

[22] H.-J. Freund, G. Pacchioni, Chem. Soc. Rev. 37 (2008), 2224.

[23] H.-J. Freund, Surf. Sci. 601 (2007), 1438.

[24] M. Sterrer, T. Risse, U. M. Pozzoni, L. Giordano, M. Heyde, H. P. Rust, G. Pacchioni, H.-J. Freund, Phys. Rev. Lett. 98 (2007), 096107.

[25] M. Sterrer, T. Risse, M. Heyde, H.-P. Rust, H.-J. Freund, Phys. Rev. Lett. 98 (2007), 206103.

[26] H. Grönbeck, J. Phys. Chem. B 110 (2006), 11977.

[27] P. Frondelius, A. Hellman, K. Honkala, H. Hakkinen, H. Grönbeck, Phys. Rev. B 78 (2008), 085426.

[28] Y.-N. Sun, Z.H. Qin, M. Lewandowski, S. Shaikhutdinov, H.J. Freund, Catal. Letters, 126 (2008), 31.

[29] K. Hayek, M. Fuchs, B. Klötzer, W. Reichl, G. Rupprechter, Topics Catal. 13 (2000) 55.

[30] G. Ertl, M.Neumann, K.M. Streit, Surf. Sci. 64 (1977) 193.

[31] K. McCrea, J. Parker, P. Chen, G. Somorjai, Surf. Sci., 494 (2001) 238.

[32] C. Lemire, R.Meyer, V.E. Nenrich, S. Shaikhutdinov, H.-J. Freund, Surf. Sci., 572 (2004) 103. 
[33] J. Libuda, A.Sandel, M. Bäumer, H. -J. Freund, Chem. Phys. Lett., 240 (1995) 429.

[34] S. Sato, Y. Ukisu, Surf. Sci. 283 (1993) 137.

[35] S. Fletcher, M. Poliakoff, J.J.Turner, Inorg. Chem. 25 (1986) 3597.

[36] R.L. Jackson, M.R. Trusheim, J. Am. Chem. Soc. 104 (1982) 6590.

[37] M P. Felicissimo, O.N. Martyanov, T. Risse, H.-J. Freund, Surf. Sci. 601 (2007) 2105

[38] T. Wadayama, H. Osano, T. Maeyama, H. Yoshida, K. Murakami, N. Todoroki, and S. Oda, J. Phys. Chem. C 112 (2008) 8944.

[39] L. Schäfer, H.-W.Wassmuth, Surf. Sci., 208 (1989) 55.

[40] A.K. Santra, D.W. Goodman, Electrochim. Acta 47 (2002) 3595.

[41] R. Imbihl, G. Ertl, Chem. Rev. 95 (1995) 697.

[42] P.J. Berlowitz, C.H.F. Peden, D.W. Goodman, J. Phys. Chem. 90 (1988) 5213.

[43] P. Mars, D.W. van Krevelen, Chem. Eng. Sci., 3 81954) 41.

[44] M.A. Vannice, Catal. Today 123 (2007) 18.

[45] P. Li, D.E. Miser, S. Rabiei, R.T. Yadav, M.R. Hajaligol, Appl. Catal. B 43 (2003) 151.

[46] S. Wagloehner, D. Reichert, D. Leon-Sorzano, P. Balle, B. Geiger, S. Kureti, J. Catal., 260 (2008) 305.

[47] A.K. Kandalam, B. Chatterjee, S.N.Khanna, B.K. Rao, P. Jena, B.V. Reddy, Surf. Sci., 601 (2007) 4873.

[48] H. Randall, R. Doepper, A. Renken, Ind. Eng. Chem. Res., 36 (1997) 2996.

[49] O. Bikondoa, C.L. Pang, R. Ithnin, C.A. Muryn, H. Onishi, G. Thornton, Nature Materials, 5 (2006), 189-192.

[50] R. Schaub, E. Wahlström, A. Rønnau, F. Besenbacher, Science 299 (2003), 377; Science 314 (2006), 925.

[51] J.L. Daschbach, Z. Dohnalek, S.-R. Liu, R.S. Smith, B.D. Kay, J. Phys. Chem. B 109 (2005), 10362.

[52] W. Huang, W. Ranke, Surf. Sci., 600 (2006), 793.

[53] L.R. Merte, J. Knudsen, L.C. Grabow, R.T. Vang, E. Lægsgaard, M. Mavrikakis, F. Besenbacher, Surf. Sci. 603 (2009), L15. 


\section{Figure captions.}

Fig. 1. Temperature programmed reaction profile of $\mathrm{CO}_{2}$ production over $\mathrm{FeO}(111) / \mathrm{Pt}(111)$ on slow heating $(1 \mathrm{~K} / \mathrm{min})$ in $40 \mathrm{mbar} \mathrm{CO}+20 \mathrm{mbar} \mathrm{O}_{2}$ balanced by $\mathrm{He}$.

Fig. 2. Kinetics of $\mathrm{CO}_{2}$ production over $\mathrm{FeO}(111) / \mathrm{Pt}(111)$ in: (a) $40 \mathrm{mbar} \mathrm{CO}+20 \mathrm{mbar} \mathrm{O}_{2}$ at indicated temperatures; (b) at stoichiometric $\mathrm{CO}: \mathrm{O}_{2}(2: 1)$ ratios at indicated total pressures at $450 \mathrm{~K}$. The results for $\mathrm{Pt}(111)$ and nm-thick $\mathrm{Fe}_{3} \mathrm{O}_{4}(111) / \mathrm{Pt}(111)$ film in $40 \mathrm{mbar} \mathrm{CO}+20$ mbar $\mathrm{O}_{2}$ at $450 \mathrm{~K}$ are shown in (b), for comparison. Time zero corresponds to the start of the sample heating $(1 \mathrm{~K} / \mathrm{s})$ from $300 \mathrm{~K}$.

Fig. 3. LEED patterns of the "as prepared" $\mathrm{FeO}(111) / \mathrm{Pt}(111)$ film (a) and after reaction at 400 (b) and $450 \mathrm{~K}$ (c) in 40 mbar $\mathrm{CO}+20 \mathrm{mbar} \mathrm{O}_{2}$ in He. The unit cell for c $(4 \times 2) \mathrm{CO}-$ $\mathrm{Pt}(111)$ structure is indicated.

Fig. 4. AES spectra of the clean $\mathrm{FeO}(111) / \mathrm{Pt}(111)$ film (top), after the reaction in 40 mbar $\mathrm{CO}+20$ mbar $\mathrm{O}_{2}$ at $450 \mathrm{~K}$ (middle) and subsequent annealing to $800 \mathrm{~K}$ for $2 \mathrm{~min}$ (bottom). The corresponding peak ratios for $\mathrm{O}(510 \mathrm{eV})$ and $\mathrm{Fe}(658 \mathrm{eV})$ are indicated.

Fig. 5. STM images (size $200 \mathrm{~nm} \times 200 \mathrm{~nm}$ ) of the as prepared $\mathrm{FeO}(111)$ film (a), after 10 minutes (b) and two hours (c) in $40 \mathrm{mbar} \mathrm{CO}+20 \mathrm{mbar}_{2}$ at $450 \mathrm{~K}$. The inset shows the atomic structure of the Moire pattern.

Fig. 6. STM images (size $500 \mathrm{~nm} \times 500 \mathrm{~nm}$ ) of the dewetted $\mathrm{FeO}(111)$ film (a) and after step-wise UHV annealing at 500 (b), 700 (c) and $800 \mathrm{~K}$ (d).

Fig. 7. (a) Time-resolved PM-IRAS spectra of the CO stretching region obtained from the $\mathrm{FeO}(111) / \mathrm{Pt}(111)$ surface at $450 \mathrm{~K}$ in a mixture of $40 \mathrm{mbar} \mathrm{CO}$ and $20 \mathrm{mbar} \mathrm{O}_{2}$ balanced by He to 1 bar. The spectrum for the $\operatorname{Pt}(111)$ surface after $120 \mathrm{~min}$ at the same conditions is shown for comparison. (b) Kinetics of $\mathrm{CO}_{2}$ formation in the gas phase and of $\mathrm{CO}$ adsorbed on $\mathrm{FeO}(111) / \mathrm{Pt}(111)$ obtained by integration of the respective PM-IRAS signals. 
Fig. 8. $\mathrm{CO}(28 \mathrm{amu})$ and $\mathrm{CO}_{2}(44 \mathrm{amu})$ signals in TPD spectra of a $\mathrm{FeO}(111) / \mathrm{Pt}(111)$ film reacted in 40 mbar $\mathrm{CO}+20$ mbar $\mathrm{O}_{2}$ for $120 \mathrm{~min}$ at indicated temperatures. The samples were cooled to $300 \mathrm{~K}$ and evacuated to $10^{5}$ mbar before exposing to UHV. The inset shows the Arrhenius plot for the integral $\mathrm{CO}$ desorption signal as a function of reaction temperature. The spectrum for clean $\mathrm{Pt}(111)$ after reaction at $450 \mathrm{~K}$ is shown as dotted line for comparison. TPD spectrum of $\mathrm{Pt}_{\mathrm{x}}(\mathrm{CO})_{\mathrm{y}}$ formed on $\mathrm{Pt}(111)$ by $\mathrm{Pt}$ deposition in $10^{6}$ mbar of $\mathrm{CO}$ at $100 \mathrm{~K}$ (dashed line) is shown to highlight a desorption feature at $\sim 380 \mathrm{~K}$.

Fig. 9. Kinetics of $\mathrm{CO}_{2}$ production at $450 \mathrm{~K}$ at different $\mathrm{CO}$ and $\mathrm{O}_{2}$ partial pressures as indicated. Full conversion can be reached at low $\mathrm{CO}: \mathrm{O}_{2}$ ratios. Note the reaction rate slows down in $\mathrm{CO}$-rich conditions $\left(\mathrm{CO}: \mathrm{O}_{2}>1\right)$.

Fig. 10. Reaction rate (a), average stoichiometry (b), degree of dewetting (c) of the spent $\mathrm{FeO} / \mathrm{Pt}$ catalysts as a function of $\mathrm{O}_{2}$ pressure in the mixture with $10 \mathrm{mbar}$ of $\mathrm{CO}$, balanced by He. Reaction temperature is $450 \mathrm{~K}$.

Fig. 11. Reaction rate (a), average stoichiometry (b), degree of dewetting (c) of the spent $\mathrm{FeO} / \mathrm{Pt}$ catalysts as a function of $\mathrm{CO}$ pressure in the mixture with 20 mbar of $\mathrm{O}_{2}$, balanced by He. The reaction rates measured after 120 min on stream as well as data for clean $\operatorname{Pt}(111)$ are also shown.

Fig. 12. STM image $(50 \mathrm{~nm} \times 50 \mathrm{~nm})$ of the $\mathrm{FeO}$ film treated in 20 mbar of $\mathrm{O}_{2}$ at $450 \mathrm{~K}$ for $10 \mathrm{~min}$, showing that the film basically maintains long-range ordering (compare Fig. 5a). 


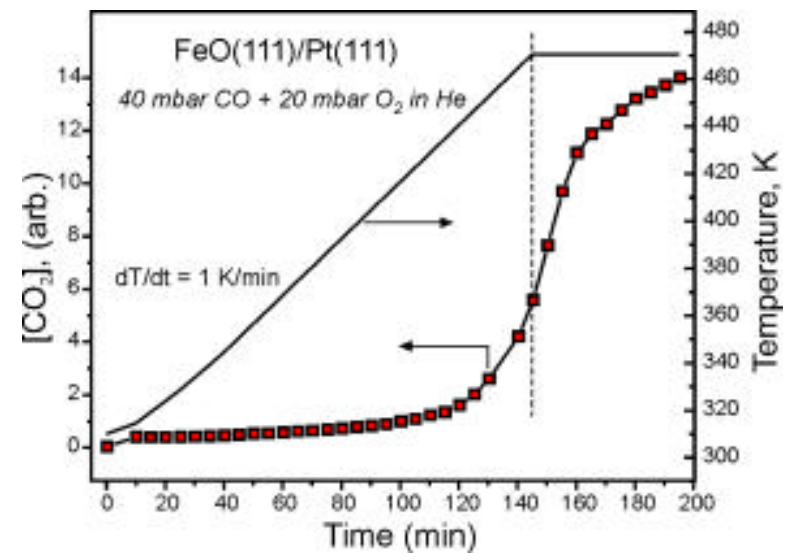

Fig. 1 

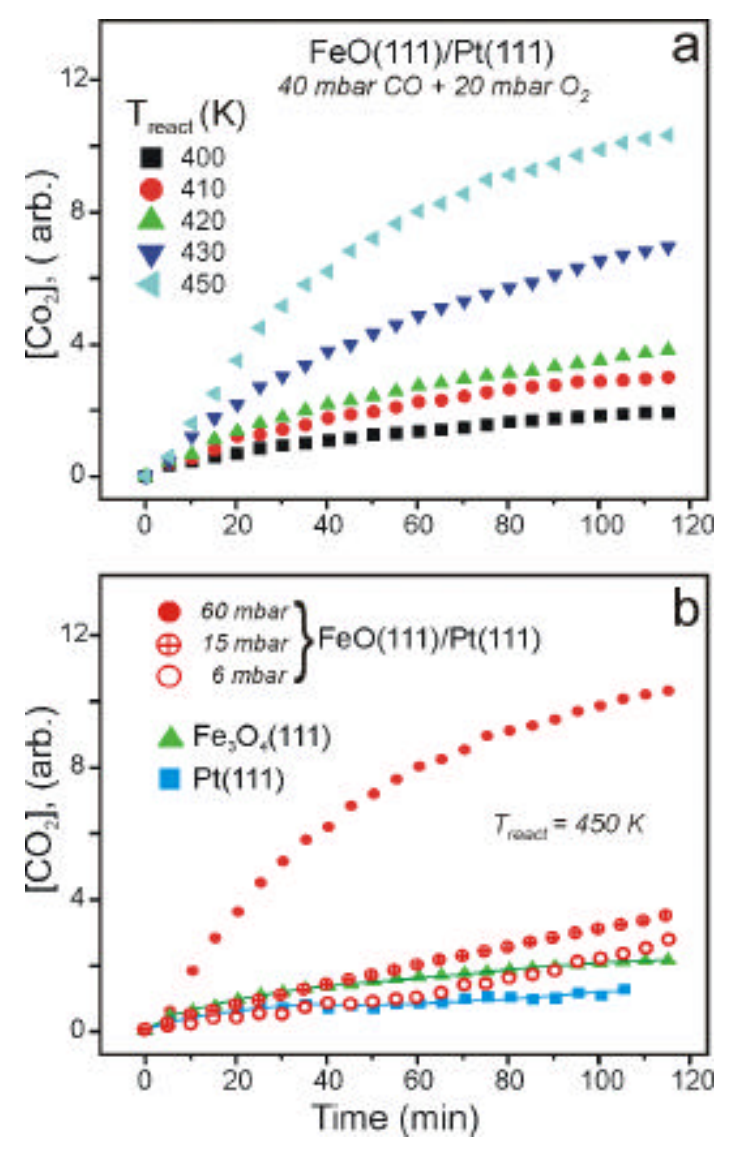

Fig. 2 

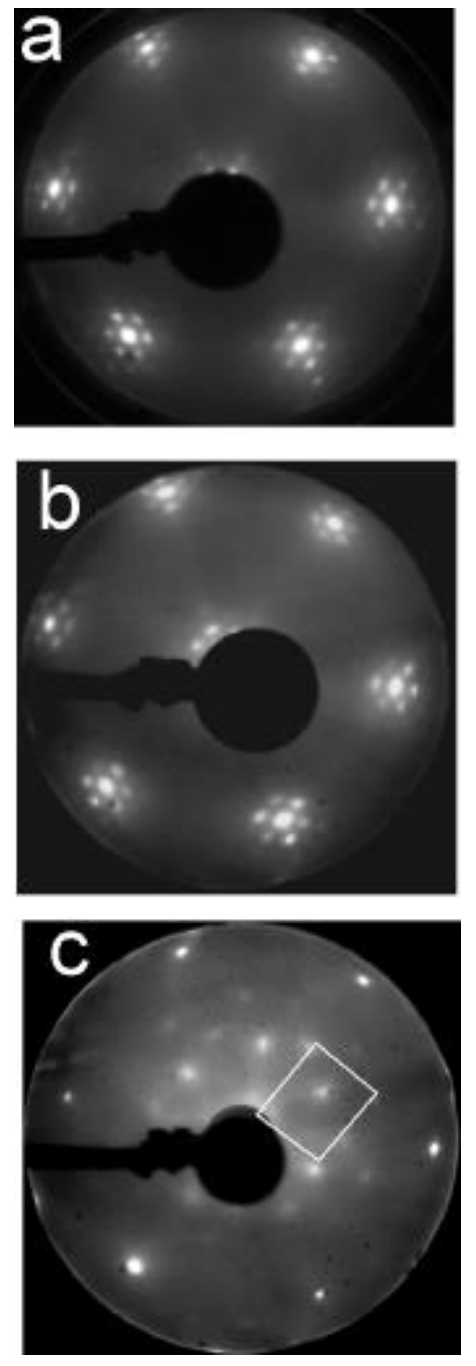

Fig. 3

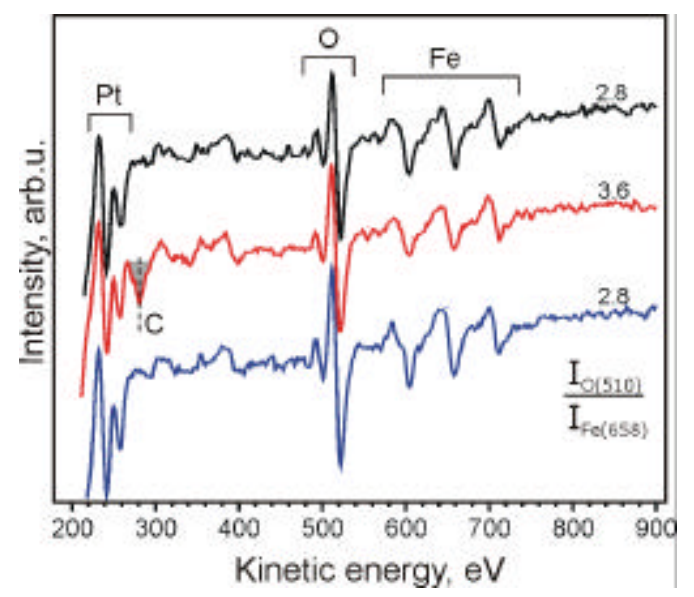

Fig. 4 

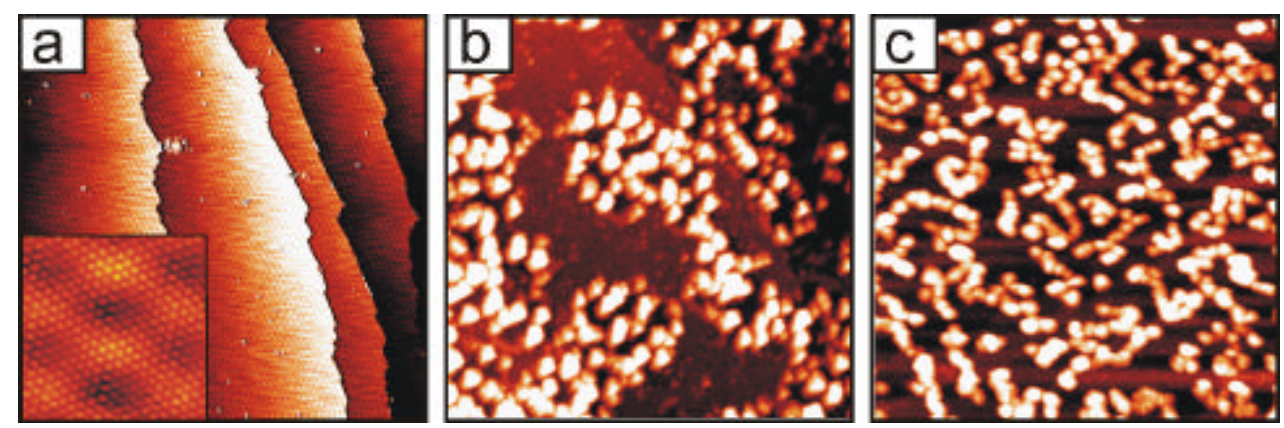

Fig. 5
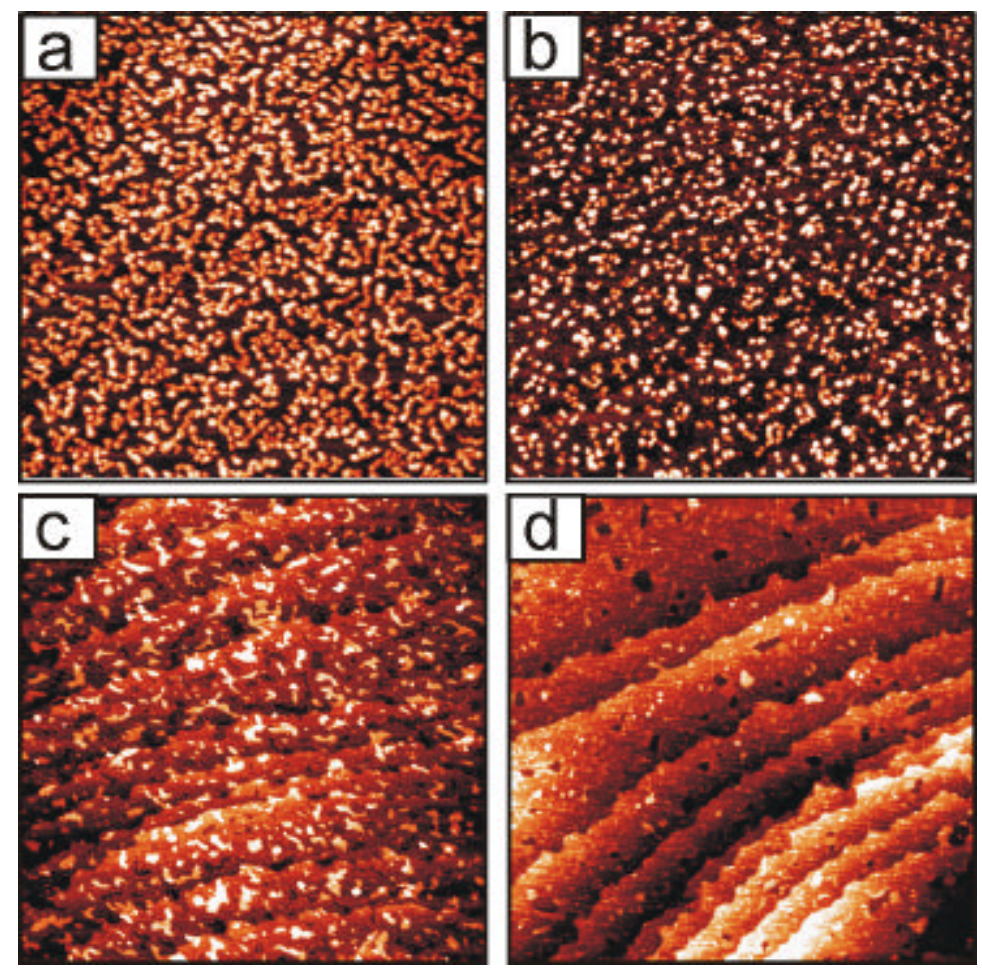

Fig. 6 

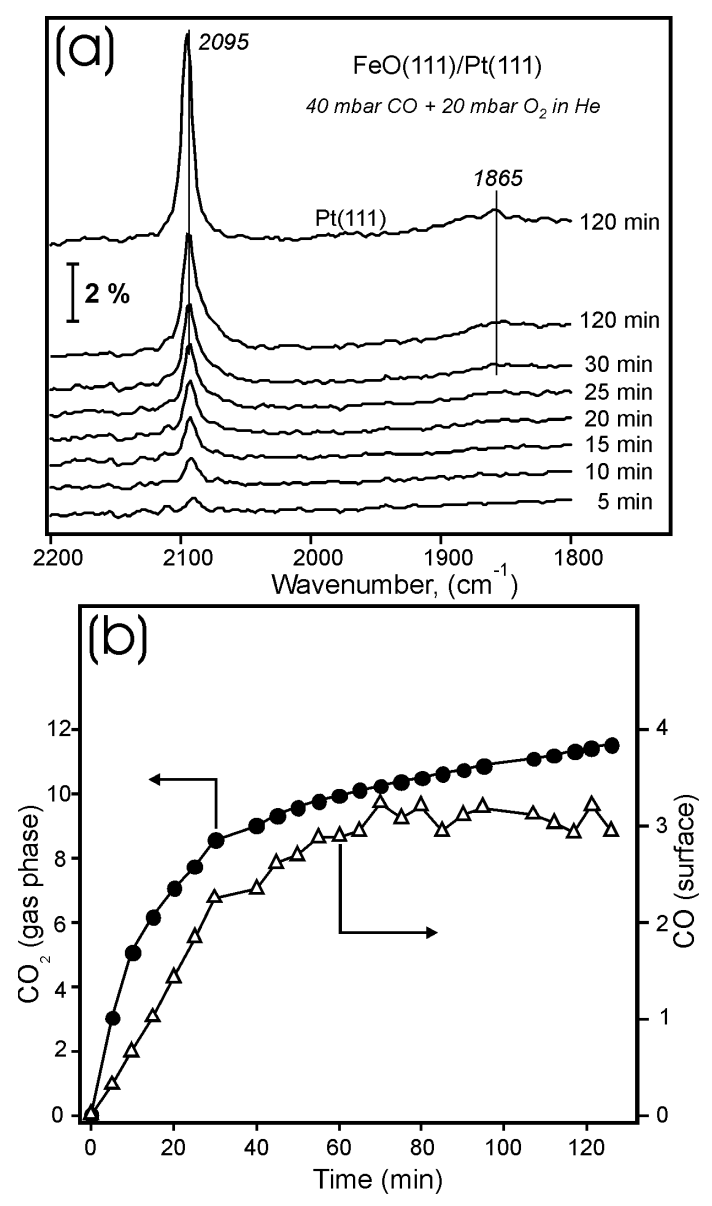

Fig. 7

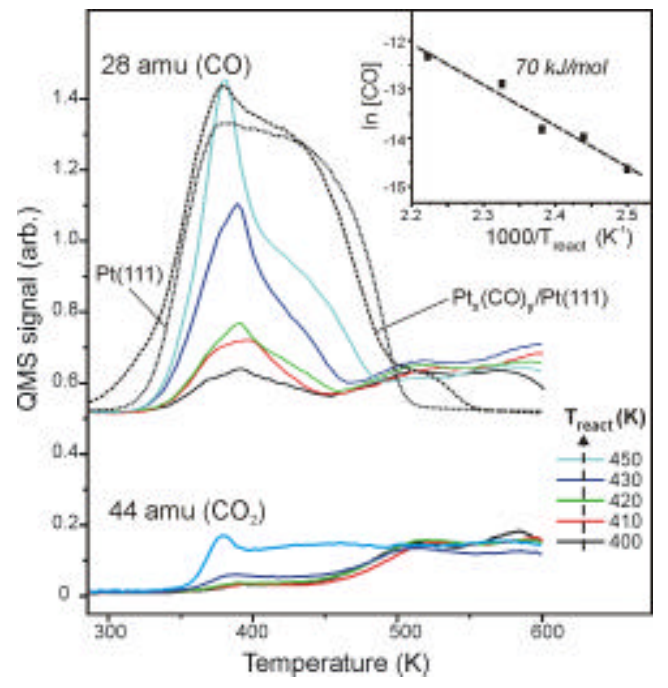

Fig. 8 

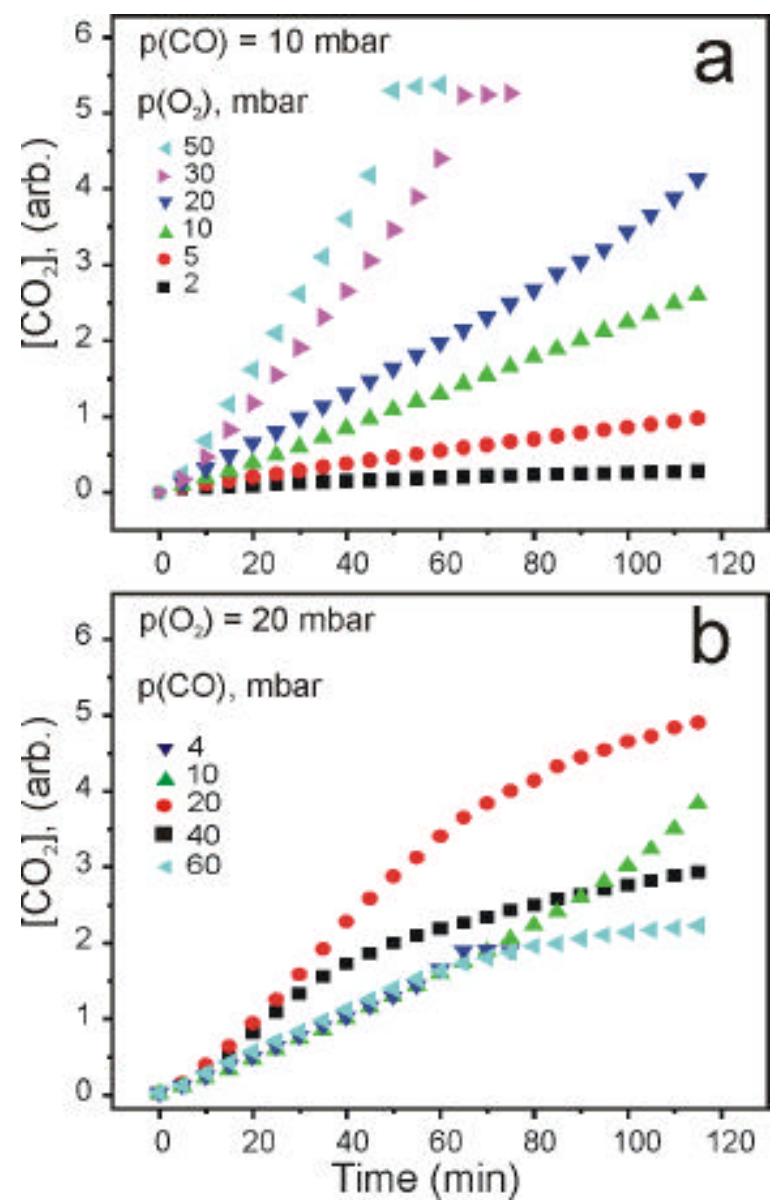

Fig. 9 

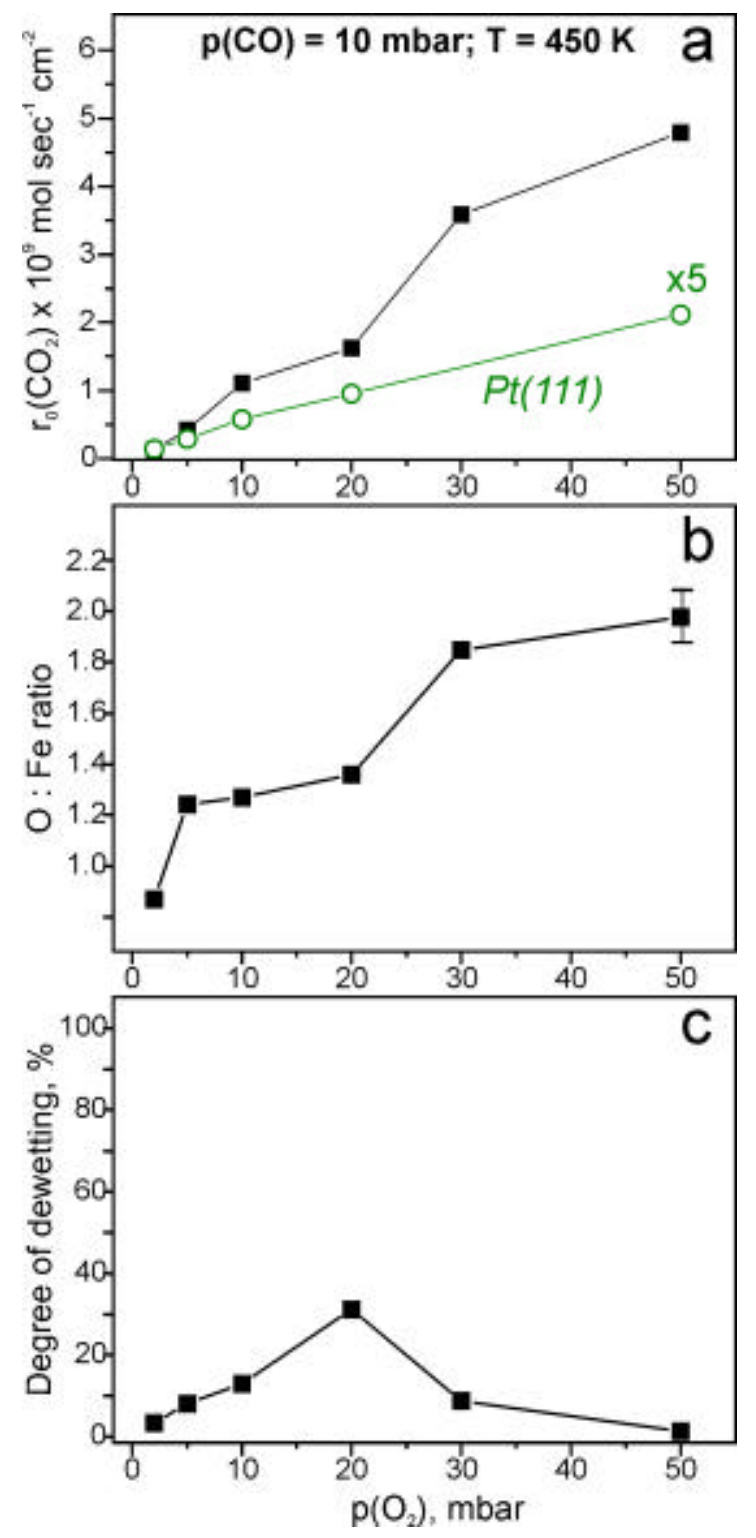

Fig. 10 


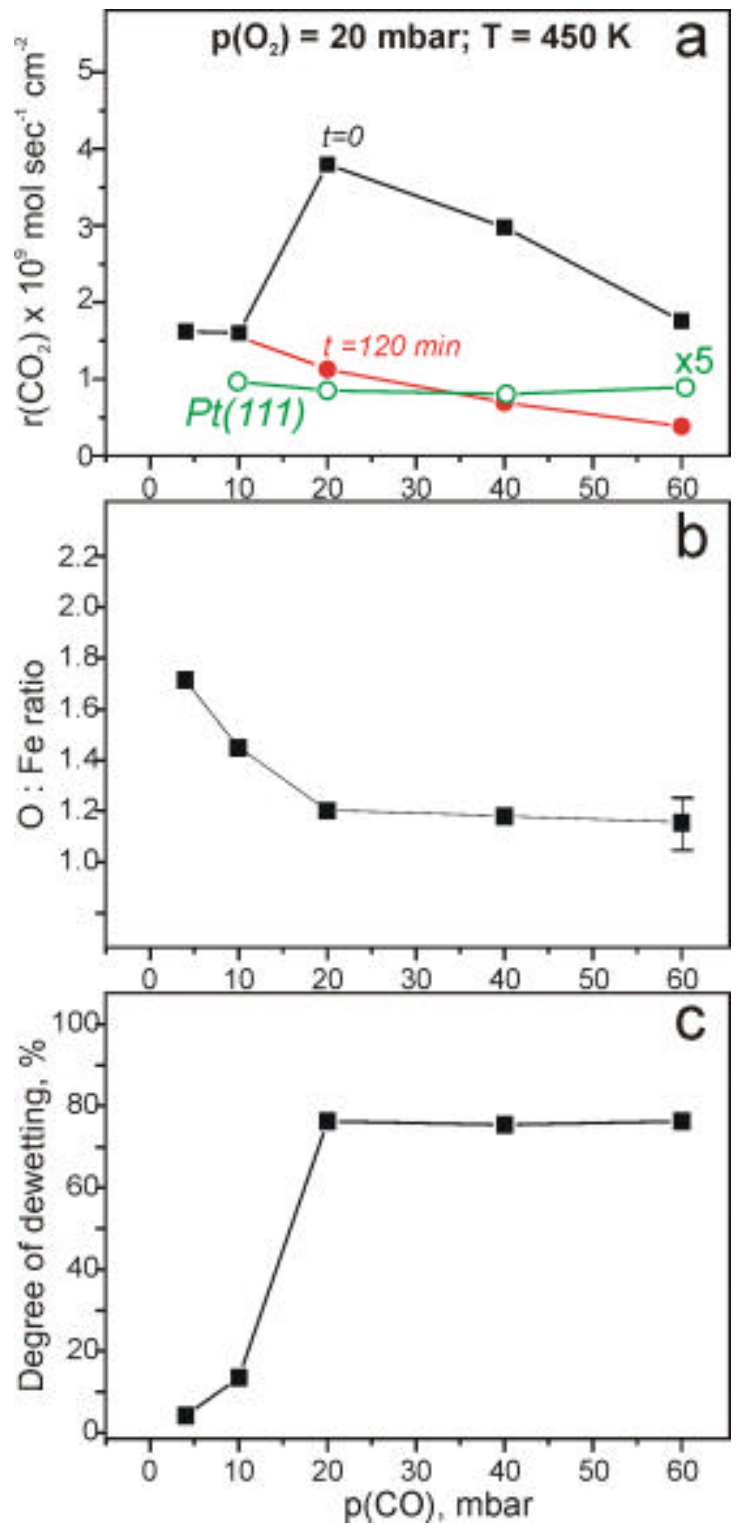

Fig. 11 


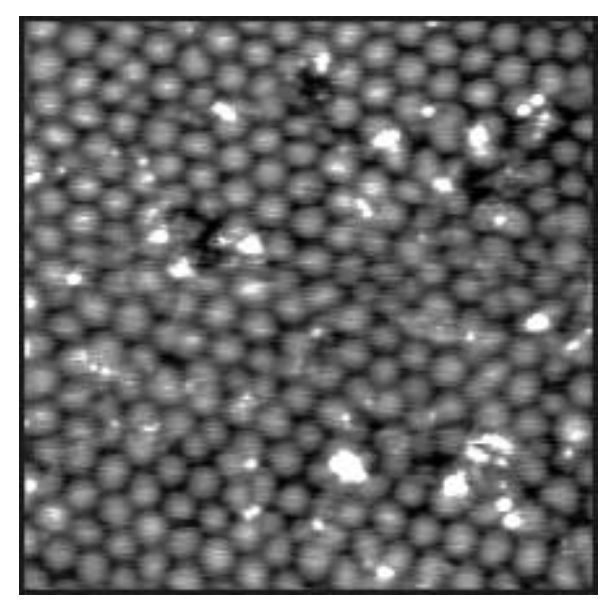

Fig. 12 